\title{
A narrative review of the pharmacology of ginsenoside compound $\mathrm{K}$
}

\author{
Tao Liu ${ }^{1,2 \#}, \mathrm{Lu}^{\mathrm{Zhu}}{ }^{1,2 \#}, \mathrm{Li} \mathrm{Wang}^{3}$ \\ ${ }^{1}$ Department of Pediatrics, The Affiliated Hospital of Southwest Medical University, Luzhou, China; ${ }^{2}$ Sichuan Clinical Research Center for Birth \\ Defects, Luzhou, China; ${ }^{3}$ Department of Pediatric Respiratory Medicine, Chengdu Women's and Children's Central Hospital, School of Medicine, \\ University of Electronic Science and Technology of China, Chengdu, China \\ Contributions: (I) Conception and design: T Liu; (II) Administrative support: L Wang; (III) Provision of study materials or patients: L Zhu; (IV) \\ Collection and assembly of data: T Liu, L Zhu; (V) Data analysis and interpretation: L Zhu; (VI) Manuscript writing: All authors; (VII) Final \\ approval of manuscript: All authors. \\ \#The authors contributed equally to this review. \\ Correspondence to: Li Wang. Department of Pediatric Respiratory Medicine, Chengdu Women's and Children's Central Hospital, School of Medicine, \\ University of Electronic Science and Technology of China, Chengdu 611731, China. Email: 625664758@qq.com.
}

Background and Objective: The ginsenoside compound K [20-o-beta-dglucopyranosyl-20 (S)protopanaxadiol; $\mathrm{CK}]$ is the main deglycosylated metabolite of ginsenoside. As a rare ginsenoside converted from the active substance of ginseng by intestinal bacteria, CK has higher biological activity than other ginsenosides. It has demonstrated diverse and intriguing biological activities, including anti-carcinogenic, anti-diabetic, anti-inflammation, anti-allergy, anti-angiogenesis, anti-aging, neuroprotective, and hepatoprotective effects. The purpose of this review was to elucidate the rich pharmacological activities and related mechanisms of ginsenoside CK in vivo and in vitro, as well as the potential therapeutic value of CK as a drug in a variety of systemically related diseases.

Methods: The PubMed database was searched for articles published in English from February 2008 to December 2021 using related keywords such as "Ginsenoside compound K", "compound K", and "CK". About 140 research papers and reports written in English were identified. These papers mainly concentrated on the pharmacological activities of CK in cancer prevention, immune regulation, diabetic improvement, central nervous system (CNS) protection, cardiovascular protection, skin improvement, and hepatoprotection.

Key Content and Findings: This paper describes the synthesis, pharmacokinetics, and adverse reactions of CK, as well as great detailed summarized of the relevant pharmacological activities. Such diverse intriguing biological properties of CK have been found.

Conclusions: On account of CK's numerous pharmacological activities and anti-carcinogenic, antiinflammation, antiallergic, anti-diabetic, anti-angiogenesis, anti-aging, neuroprotective, and hepatoprotective effects, strong evidence is available for CK as a preventive or therapeutic agent for various diseases. However, further studies are needed to evaluate the safety and effectiveness of CK as a drug and its application in the medical field.

Keywords: Ginsenoside compound K; pharmacology; cancer; diabetes

Submitted Dec 03, 2021. Accepted for publication Feb 18, 2022.

doi: 10.21037/atm-22-501

View this article at: https://dx.doi.org/10.21037/atm-22-501 


\section{Introduction}

Ginseng is a traditional Chinese herb with a long history of use in traditional Chinese medicine (TCM). It has powerful tonic effects and is widely used in various medicines (1). With the development of extraction technology, the most pharmacologically active constituents of ginseng have been reported to be ginsenosides, a group of triterpene saponins (2). To date, more than 150 active constituents have been extracted from the roots, stems, leaves, fruits, and flowers of ginseng (3). Studies have reported that ginsenosides are not absorbed intact in vivo, but need to be metabolized by intestinal microflora before being absorbed through the intestinal tract (4-6). Other studies have shown that deglycosylation is the major metabolic pathway involved in the transformation of ginsenosides to deglycosylated ginsenoside, which have higher biological activity than ginsenosides $(7,8)$. Compound K (CK, 20-o-beta-d-glucopyranosyl-20 (S)protopanaxadiol, $\mathrm{C}_{36} \mathrm{H}_{62} \mathrm{O}_{8}$ ) is the major deglycosylated metabolite of ginsenoside (8). Recent in vivo and in vitro studies have reported that $\mathrm{CK}$ is involved in multiple pharmacological processes and possesses anticarcinogenic (9), anti-diabetic (10), anti-inflammatory (11), anti-allergic (12), anti-angiogenic (13), anti-aging (14), and hepatoprotective effects (15), as well as effects on the central nervous system (CNS) (16). In particular, many studies have investigated its pharmacological effects. However, no study has investigated the complete integration of the pharmacological activity of CK. Therefore, we reviewed the pharmacological activity and associated mechanisms of CK in detail and updated the literature in recent years. It is expected to be helpful in developing potential agents to treat related diseases.

We present the following article in accordance with the Narrative Review reporting checklist (available at https:// atm.amegroups.com/article/view/10.21037/atm-22-501/rc).

\section{Methods}

The PubMed database was searched for articles published in English from February 2008 to May 2021 using related keywords such as "Ginsenoside compound K", "compound K", and "CK". The information used to write this paper was collected from the sources listed in Table 1.

\section{Biotransformation, pharmacokinetics, and safety of CK}

The ginsenoside CK belongs to the family of tetracyclic dammarane-type triterpenoid saponins. Based on their chemical structure, dammarane group ginsenosides are classified into two types: protopanaxadiol (PPD), which includes Ra1, Ra2, Ra3, Rb1,Rb2, Rb3, Rc, Rd, Rg3, Rh2, $\mathrm{F} 2$, and $\mathrm{CK}$, and protopanaxatriol (PPT), which includes Re, Rf, Rg1, Rg2, Rh1, and F1 (Figure 1) $(17,18)$.

Japanese researchers originally isolated CK from a mixture of Rb1, Rb2, and Rc, which were hydrolyzed from ginseng by a soil bacterium (19). Although its structure was identified in 1972, the finding that Rb1 and $\mathrm{Rb} 2$ were metabolized into $\mathrm{CK}$ by intestinal bacteria in rats via a specific pathway was reported 20 years later $(20,21)$. Hasegawa et al. $(22,23)$ investigated the specific transformation pathway of CK by intestinal microflora and speculated that CK was the most likely form of protopanaxadiol saponins that underwent intestinal absorption. The specific metabolic pathways of Rb1 and $\mathrm{Rb} 2$ metabolism to CK by intestinal bacteria are shown in Figure 2 (23,24). After the oral administration of Rb1 to rats, a high concentration of CK, but no Rb1, was found to be present in their intestinal contents, plasma, and urine (25-27). Researchers have focused on the biological functions of CK and methodology for the effective production of CK from major ginsenosides.

The bioavailability of ginsenosides without transformation and modification suggests low absorption in the intestinal tract $(28,29)$. After the oral administration of ginsenosides, a series of biological transformations occur in the intestinal tract, and they are converted into deglycosylated metabolites with higher biological activities than their precursor compounds (7). Other studies have reported that intestinal bacteria or soil fungi around ginseng roots as well as some microorganisms hydrolyze ginsenosides to form CK $(30,31)$. The various methods for microbial conversion are summarized in Table 2 (7).

The enzyme $\beta$-glucosidase, with a molecular weight of $320 \mathrm{kDa}$ and 4 identical subunits $(80 \mathrm{kDa})$, is a key enzyme in the hydrolysis of Rb1 into CK (45) and was initially purified from metabolizing bacteria isolated from human intestinal feces (46). Subsequently, $\beta$-glucosidase that promoted more specific and effective transformation 
Table 1 The search strategy summary

\begin{tabular}{ll}
\hline Items & Specification \\
\hline Date of search & 30, July 2021 \\
$\begin{array}{l}\text { Database and other sources searched } \\
\text { Search terms used }\end{array}$ & $\begin{array}{l}\text { Ginsenoside compound K [all fields] OR compound K [all fields] OR CK [all fields] OR G-CK [all } \\
\text { fields] } \\
\text { Timeframe }\end{array}$ \\
Inclusion and exclusion criteria & All study type will be included \\
Selection process & Study selection will be performed by Tao Liu and Lu Zhu independently. Any disagreement about \\
& the inclusion of studies will be resolved through discussion
\end{tabular}

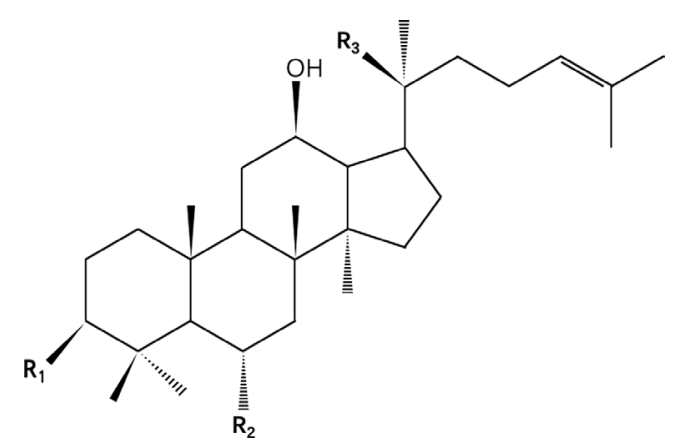

Figure 1 Chemical structures of ginsenosides.

\begin{tabular}{|c|c|c|c|c|}
\hline \multicolumn{2}{|c|}{ Ginsenoside } & R1 & R2 & R3 \\
\hline \multirow{9}{*}{ PPD-type } & Compound $\mathrm{K}$ & $\mathrm{OH}$ & $\mathrm{H}$ & O-Glc \\
\hline & $\mathrm{Rb} 1$ & O-Glc-Glc & $\mathrm{H}$ & O-Glc-Glc \\
\hline & $\mathrm{Rb} 2$ & O-Glc-Glc & $\mathrm{H}$ & O-Glc-Arap \\
\hline & $\mathrm{Rc}$ & O-Glc-Glc & $\mathrm{H}$ & O-Glc-Araf \\
\hline & $\mathrm{Rd}$ & O-Glc-Glc & $\mathrm{H}$ & O-Glc \\
\hline & Rg3 & O-Glc-Glc & $\mathrm{H}$ & $\mathrm{OH}$ \\
\hline & F2 & O-Glc & H & O-Glc \\
\hline & $\mathrm{Rh} 2$ & O-Glc & $\mathrm{H}$ & $\mathrm{OH}$ \\
\hline & PPD & $\mathrm{OH}$ & $\mathrm{H}$ & $\mathrm{OH}$ \\
\hline \multirow{7}{*}{ PPT-type } & $\operatorname{Re}$ & $\mathrm{OH}$ & O-Glc-Rha & $\mathrm{OH}$ \\
\hline & $\mathrm{Rf}$ & $\mathrm{OH}$ & O-Glc-Glc & O-Glc \\
\hline & Rg1 & $\mathrm{OH}$ & O-Glc & $\mathrm{OH}$ \\
\hline & Rg2 & $\mathrm{OH}$ & O-Glc-Rha & O-Glc \\
\hline & Rh1 & $\mathrm{OH}$ & O-Glc & $\mathrm{OH}$ \\
\hline & F1 & $\mathrm{OH}$ & $\mathrm{OH}$ & O-Glc \\
\hline & PPT & $\mathrm{OH}$ & $\mathrm{OH}$ & $\mathrm{OH}$ \\
\hline
\end{tabular}

Glc, glucose

Arap, arabinose in pyranose form Araf, arabinose in furanose form Rha, rhamnose was found and purified in the soil of ginseng fields $(47,48)$. Later, researchers extracted $\beta$-glycosidase from Sulfolobus solfataricus and other acid-resistant hot microbiota, and its degree of transformation and efficiency were higher than those previously reported (49-51). Subsequent studies focused on the activity and conversion efficiency associated with the design and modification of enzymes $(45,52,53)$. Shin et al. (45) designed W361f, a variant of $\beta$-glycosidase, which had 4.2 times the activity of Rd, and 3.7 times higher catalytic efficiency and 3.1 times lower binding energy than the wild-type enzyme. They also found that semi-rational design was a useful tool to enhance the hydrolytic activity of $\beta$-glycosidase. Therefore, it is important to discover and modify catalytic enzymes to improve the utilization and production efficiency of CK (54).

As intestinal microflora is important for the biotransformation and pharmacological activity of CK, it is necessary to study the metabolic pathways that regulate intestinal microflora. Recent studies have indicated that western dietary habits and NUTRIOSE (ROQUETTE Frères, Lestrem, France) were more likely to improve the concentration level of CK $(55,56)$. Furthermore, a study of human metabolism found that a high-fat diet significantly accelerated and increased the absorption of CK, and that the concentration level of CK in women was higher than that in men (57). A randomized double-blind study 


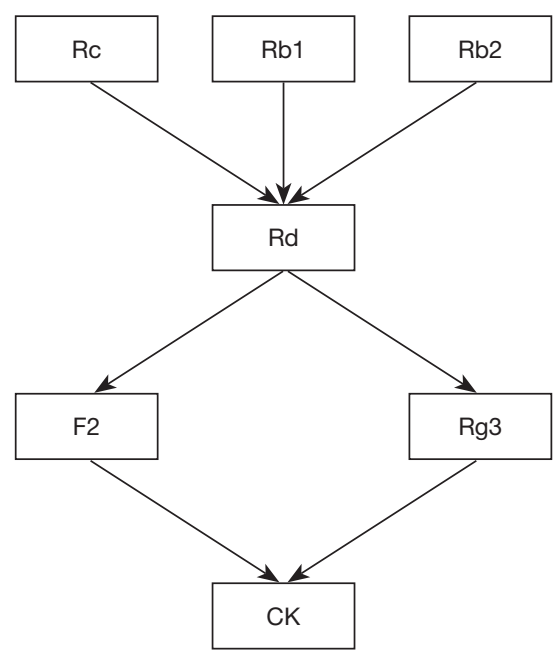

Figure 2 Biotransformation of major PPD-type ginsenosides to CK. PPD, protopanaxadiol; CK, 20-o-beta-d-glucopyranosyl-20 (S)-protopanaxadiol.

reported the gender- and food-related impacts on CK pharmacokinetics (58).

Another pharmacokinetic study of CK reported the drug levels in blood samples of 10 healthy men 36 hours after the administration of Korean ginseng extract (59). The mean maximum plasma concentration $\left(C_{m a x}\right)$ of CK was significantly higher than the level of $\mathrm{Rb} 1(8.35 \pm 3.19$ vs. $3.94 \pm 1.97 \mathrm{ng} / \mathrm{mL}$ ) and the mean time to reach the $C_{\max }$ $\left(T_{m a x}\right)$ of CK was longer than that of Rb1 $(12.20 \pm 1.81$ vs. $8.70 \pm 2.63 \mathrm{~h}$ ). The delay in the absorption of CK supports the idea that intestinal microflora transforms Rb1 to CK. The plasma half-life $\left(t_{1 / 2}\right)$ of CK was 7 times shorter than that of $\mathrm{Rb} 1$. These results indicate that the pharmacokinetics of CK are significantly different from those of Rb1. In another study (58), 76 participants received CK or placebo in 7 single oral doses $(25,50,100$, $200,400,600,800 \mathrm{mg}$ ) while fasting; the time range to reach $T_{\max }$ was $1.5-6.0 \mathrm{~h}$, and the exposure to CK increased linearly in the range of 100 to $400 \mathrm{mg}$. The steadystate was reached after the seventh administration and no severe adverse events (AEs) were observed. The most reported AEs were watery stool (diarrhea) and bellyache, and all AEs were mild or moderate, most of them were disappeared or reversible without any treatment $(57,58)$. These results indicated that CK was safe and welltolerated over the treatment period.

In a toxicity study, the oral administration of CK to rats and mice did not cause death or toxicity at the maximum doses of 8 and $10 \mathrm{~g} / \mathrm{kg}$, respectively (60). In a 26 -week toxicity study, rats were administered CK at doses of 13,40 , or $120 \mathrm{mg} / \mathrm{kg}$ and observed at 26 weeks and at 4-week recovery periods. Compared with the control group, asthenia, fur-loss, hypoactivity and body weight reduction were observed in $120 \mathrm{mg} / \mathrm{kg}$ male rat group, the hepatotoxicity and nephrotoxicity including elevated serum ALT and ALP, higher liver relative weight with similar histological changes to the 90-day sub-chronic intravenous $\mathrm{CK}$ in rat, and higher kidney relative weight with no histological changes were also showed in $120 \mathrm{mg} / \mathrm{kg}$ male rat group, but the toxicity were reversible after 4 -week recovery. No abnormalities in routine activity, laboratory markers, and histopathological examination were found in the 13 and $40 \mathrm{mg} / \mathrm{kg}$ CK groups (60). In addition, the no observed harmful effect level was $40 \mathrm{mg} / \mathrm{kg}$ in males and $120 \mathrm{mg} / \mathrm{kg}$ in female rats. In a beagle toxicity study, animals in the $36 \mathrm{mg} / \mathrm{kg}$ group showed reversible hepatotoxicity and significant weight loss during the study period. Animals in the 4 and $12 \mathrm{mg} / \mathrm{kg}$ groups did not show any significant toxicity (61).

CK has been shown to be safe and well tolerated in animal and human subjects. These preclinical results suggest that the liver may be a toxic organ for CK. Although the relative weight of the kidney was high, there was no histological change, but nephrotoxicity should be noted. CK-related AEs in clinical trials were diarrhea and abdominal pain. Drug-related AEs is common for druginduced diarrhea. There are few clinical trials on CK and few reports on CK-related AEs. Therefore, further studies are needed to investigate the mechanisms of CK-induced toxicity, especially hepatotoxicity, and GCK-induced gastrointestinal tract.

\section{Pharmacological properties of CK}

The numerous pharmacological effects of CK, including cancer prevention (62), immune regulation (63), diabetic improvement (64), CNS protection (65), cardiovascular protection (66), skin improvement (67), and hepatoprotection (68) have been demonstrated in vitro and in vivo using animal models. The detailed pharmacological effects of CK are discussed below. The major functions and action targets of CK are summarized in Tables 3,4.

\section{Anticarcinogenic effects of CK}

The number of cancer patients is increasing annually; 
Table 2 Production of CK by microbial conversion

\begin{tabular}{|c|c|c|c|c|}
\hline Microorganism classification & Transformation pathways & Source & $\begin{array}{l}\text { Processing } \\
\text { condition }\end{array}$ & Reference \\
\hline $\begin{array}{l}\text { Bifidobacterium K-103 and } \\
\text { Eubacterium A-44 }\end{array}$ & $\mathrm{Rc} \rightarrow \mathrm{Rd} \rightarrow \mathrm{CK}$ & Human feces & $37^{\circ} \mathrm{C}, \mathrm{pH} 7.0$ & Bae et al. (32) \\
\hline $\begin{array}{l}\text { Bifidobacterium K-506 and } \\
\text { Bacteroides } \mathrm{HJ}-15\end{array}$ & $\mathrm{Rc} \rightarrow \mathrm{M}_{\mathrm{b}} \rightarrow \mathrm{CK}$ & Human feces & $37^{\circ} \mathrm{C}, \mathrm{pH} 7.0$ & Bae et al. (32) \\
\hline Bifidobacterium sp. Int57and SJ32 & $\mathrm{Rb} 2$ and $\mathrm{Rc} \rightarrow \mathrm{Rd}$ and $\mathrm{F} 2 \rightarrow \mathrm{CK}$ & Human feces & $37^{\circ} \mathrm{C}, \mathrm{pH} 5.0$ & Chi et al. (30) \\
\hline Aspergillus niger & $\begin{array}{l}\mathrm{Rb} 2 \rightarrow \mathrm{Compound} \mathrm{O} \text { and Compound } \\
\mathrm{Y} \rightarrow \mathrm{CK} ; \mathrm{Rc} \rightarrow \mathrm{Mc} \rightarrow \mathrm{CK}\end{array}$ & - & $37^{\circ} \mathrm{C}, \mathrm{pH} 5.0$ & Chi et al. (30) \\
\hline Esteya vermicola CNU120806 & $\mathrm{Rd} \rightarrow \mathrm{F} 2 \rightarrow \mathrm{CK}$ & $\begin{array}{l}\text { Nematodes in } \\
\text { forest soil }\end{array}$ & $50^{\circ} \mathrm{C}, \mathrm{pH} 5.0$ & Hou et al. (33) \\
\hline Fusarium sacchari & P. notoginseng saponins $\rightarrow \mathrm{CK}$ & $\begin{array}{l}\text { Soil around } \\
\text { ginseng roots }\end{array}$ & $30^{\circ} \mathrm{C}, \mathrm{pH} 5.5$ & Han et al. $(35,36)$ \\
\hline Fusarium moniliforme & P. notoginseng saponins $\rightarrow \mathrm{CK}$ & - & - & Yang et al. (37) \\
\hline Cladosporium cladosporioides & $\mathrm{Rb} 1 \rightarrow \mathrm{Rd}$ or gypenoside XVII $\rightarrow \mathrm{F} 2 \rightarrow \mathrm{CK}$ & - & $30^{\circ} \mathrm{C}, \mathrm{pH} 7.0$ & Wu et al. (38) \\
\hline Acremonium strictum & $\mathrm{Rb} 1 \rightarrow \mathrm{CK}$ & $\begin{array}{l}\text { Soil around } \\
\text { ginseng roots }\end{array}$ & - & Chen et al. (39) \\
\hline Aspergillus niger g. 848 & $\mathrm{Rb} 1 \rightarrow \mathrm{Rd} \rightarrow \mathrm{F} 2 \rightarrow \mathrm{CK}$ & Chinese koji & $30^{\circ} \mathrm{C}, \mathrm{pH} 5.0$ & Liu et al. (40) \\
\hline Aspergillus niger & P. notoginseng saponins $\rightarrow \mathrm{CK}$ & - & - & Zhou et al. (41) \\
\hline
\end{tabular}

“-” indicates not mentioned. CK, 20-o-beta-d-glucopyranosyl-20 (S)-protopanaxadiol.

however, an effective cancer treatment is still lacking and no specific drug can cure cancer (138). Thus, the identification of new therapeutic drugs for cancer is urgent. The antitumor effects of $\mathrm{CK}$ are different in vivo and in vitro. Several studies have reported the cytotoxic and growthinhibiting effects of CK on tumor cells, whereas other studies have reported that $\mathrm{CK}$ inhibits tumor cell metastasis and tumor growth $(70,79,87,88,90,139)$. Therefore, CK may be a potentially important anticancer drug.

\section{Inhibition of tumor growth by CK}

In an in vivo study, CK significantly inhibited the growth of nasopharyngeal carcinoma (HK-1) tumors (91). On the 5 th day after treatment, the tumor size in the CK treated group was $25.6 \%$ smaller than that in the control group (91). Also, CK dose-dependently reduced the tumor growth of colorectal cancer (HCT-116) (79) and significantly inhibited tumor growth in an athymic nude mouse xenograft model of colorectal cancer cells (HCT116, SW-480, HT-29). At 3 weeks after CK treatment; the high-dose group $(30 \mathrm{mg} / \mathrm{kg})$ had a stronger antitumor effect compared with low-dose group $(15 \mathrm{mg} / \mathrm{kg})$, which was dose- and time-dependent (77). These studies suggested that CK might prevent or treat colorectal cancer (77). Furthermore, CK inhibited the growth and colony formation of cancer cells in mice transplanted with human liver cancer cells and boosted the anti-tumor effect of gamma rays in a nude mouse xenograft human lung cancer cell (NCI-H460) model, indicating that it might be an adjuvant of radiotherapy for tumor treatment $(71,74)$. 
Table 3 Anticarcinogenic effects of CK

\begin{tabular}{|c|c|c|c|}
\hline Cancer type & Cell lines & Mode of action & Ref. \\
\hline \multirow{2}{*}{ Lung cancer } & & CK inhibited growth via HIF-1 $\alpha$-mediated glucose metabolism & (70) \\
\hline & $\mathrm{HCl}-\mathrm{H} 460$ & CK induced apoptosis via ROS & (71) \\
\hline \multirow[t]{2}{*}{ Liver cancer } & MHCC97-H & CK induced apoptosis via Fas and mitochondria mediated caspase-dependent pathway & $(72)$ \\
\hline & HIT & $\mathrm{CK}$ attenuated metastatic growth via translocation of NF-кB p65 and reduction of MMP-2/9 & $(73)$ \\
\hline \multirow[t]{8}{*}{ Colon cancer } & HCT-116, HT-29 & CK blocked cell cycle at the G1 phase and had antiproliferative effects & $(75)$ \\
\hline & & $\begin{array}{l}\text { CK enhanced sensitivity to TRAIL-induced apoptosis via autophagy-dependent and } \\
\text {-independent DR5 upregulation }\end{array}$ & (76) \\
\hline & HCT-116 & $\begin{array}{l}\text { CK induced apoptosis and cycle arrest via down-regulation of CDC25A, CDK4/6, cyclin } \\
\text { D1/3, and up-regulation of p53/p21, FoxO3a-p27/p15, and Smad3 }\end{array}$ & $(77)$ \\
\hline & & CK enhanced the effects of fluorouracil & $(79)$ \\
\hline & HT-29 & $\begin{array}{l}\text { CK induced mitochondria-dependent and caspase-dependent apoptosis via the generation } \\
\text { of ROS }\end{array}$ & $(80)$ \\
\hline & & CK inhibited growth and inducing apoptosis via inhibition of histone deacetylase activity & (81) \\
\hline & & CK induced apoptosis via CAMK-IV/AMPK pathways & (82) \\
\hline & SW-480 & CK induced apoptosis and cycle arrest & (83) \\
\hline \multirow[t]{2}{*}{ Brain tumors } & U87MG, U373MG & CK inhibited growth, migration, and stemness via PI3K/ Akt/mTOR pathway & (84) \\
\hline & & $\begin{array}{l}\text { CK suppressed phorbol ester-induced MMP- } 9 \text { expression by inhibiting AP-1 and MAPK } \\
\text { signaling pathways }\end{array}$ & (85) \\
\hline Osteosarcoma & MG-63 & CK inhibited migration and invasion via the $\mathrm{PI3K} / \mathrm{mTOR} / \mathrm{p} 70 \mathrm{~S} 6 \mathrm{~K} 1$ signaling pathway & (90) \\
\hline $\begin{array}{l}\text { Nasopharyngeal } \\
\text { carcinoma }\end{array}$ & $\mathrm{HK}-1$ & CK induced apoptosis via activation of apoptosis-inducing factor & (91) \\
\hline Bladder cancer & T24 & CK induced apoptosis via the ROS-mediated p38 MAPK pathway & (92) \\
\hline \multirow[t]{3}{*}{ Leukemia } & HL-60 & CK induced apoptosis via the caspase-8-dependent pathway & (9) \\
\hline & U937 & $\begin{array}{l}\text { CK induced G1 phase arrest of the cell cycle via up-regulation of p12 and activation of } \\
\text { JNK }\end{array}$ & $(58)$ \\
\hline & Kasumi-1, MV4-11 & CK inhibited growth via inhibition of synthesis & (93) \\
\hline Breast cancer & MCF-7 & CK induced programmed necrosis via GSK3 $\beta$ & (94) \\
\hline Myeloma & U266 & CK induced apoptosis via inhibition of JAK1/STAT3 signaling & (95) \\
\hline
\end{tabular}

CK, Ginsenoside compound K; AMPK, adenosine monophosphate protein kinase; mTOR, mammalian target of rapamycin; JNK, c-Jun $\mathrm{N}$-terminal kinase; ROS, reactive oxygen species; MMP, metalloproteinase; HIF, hypoxia inducible factor; STAT, signal transducer and activator of transcription; TRAIL, related apoptosis-inducing ligand; DR5, death receptor; CDC, recombinant cell division cycle protein; CDK, cyclin-dependent kinases; FoxO3a, Forkhead box O3; Smad3, drosophila mothers against decapentaplegic; CAMK-IV, calmodulinactivated protein kinase; PI3K, phosphatidylinositol 3-kinase; Akt, protein kinase B; AP-1, activated protein-1; MAPK, mitogen-activated protein kinase; SDF-1, stromal cell derived factors-1; GSK3 $\beta$, glycogen synthase kinase; JAK, janus kinase. 
Table 4 Pharmacology of CK

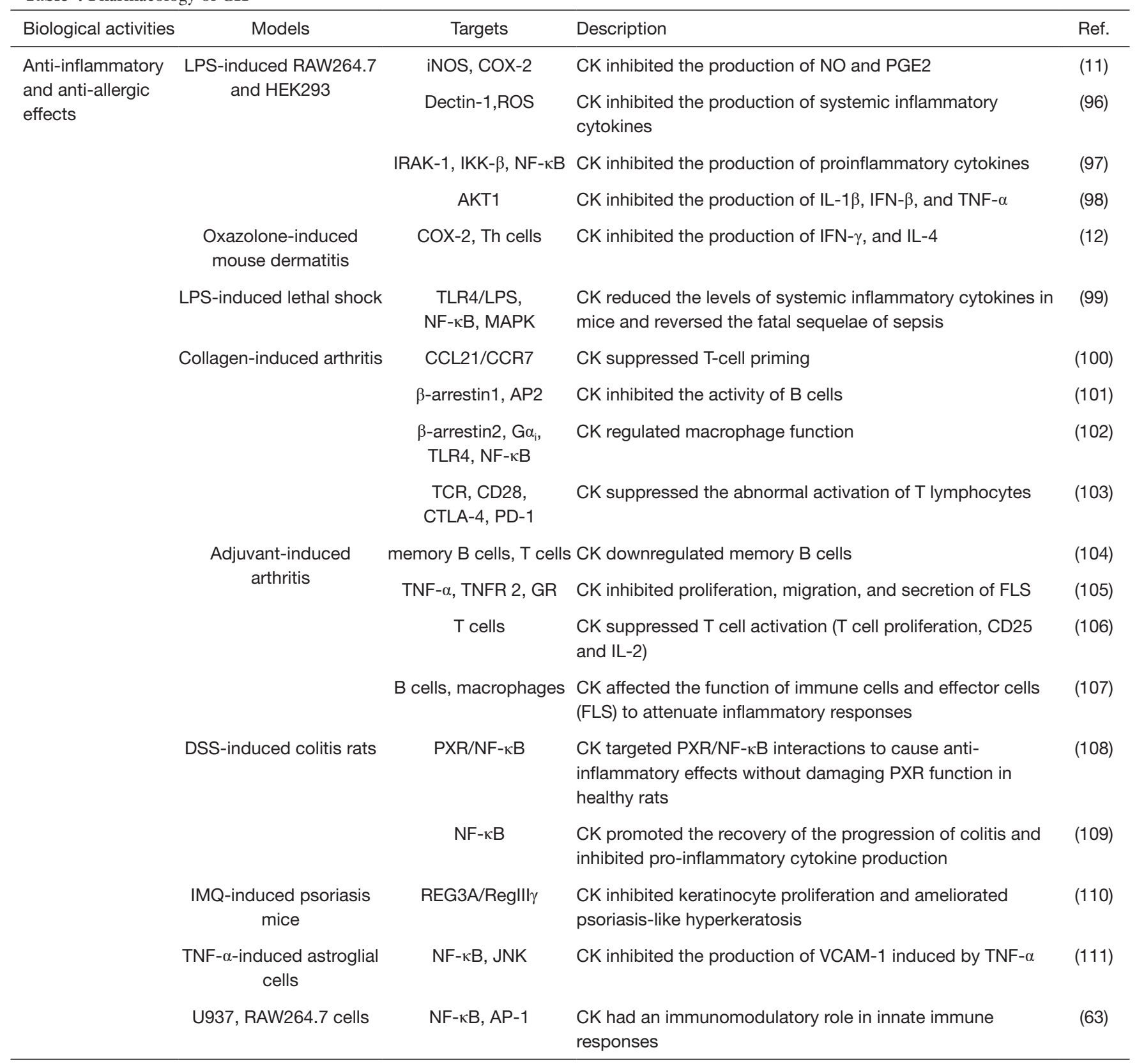

Table 4 (continued) 
Table 4 (continued)

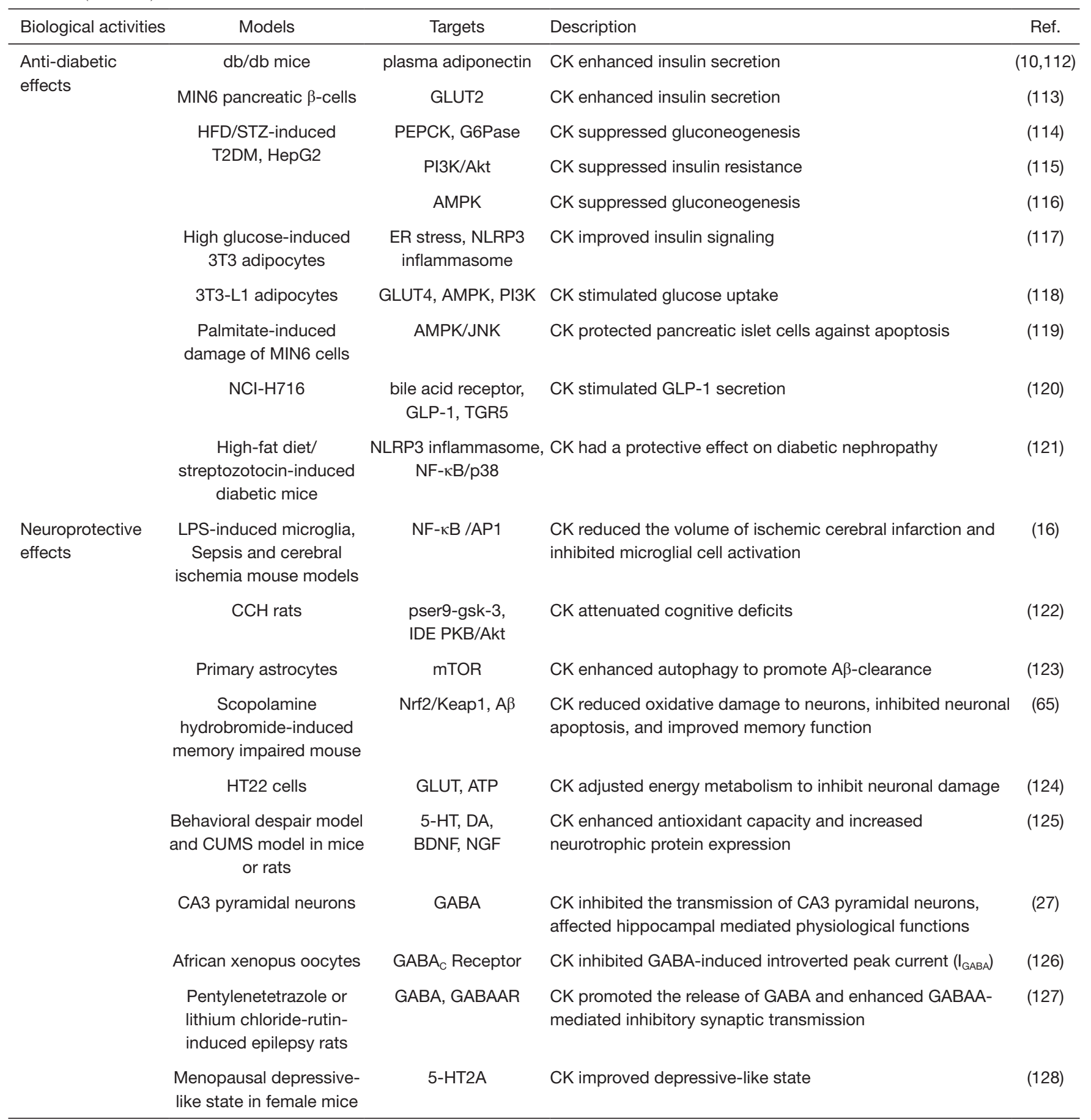

Table 4 (continued) 
Table 4 (continued)

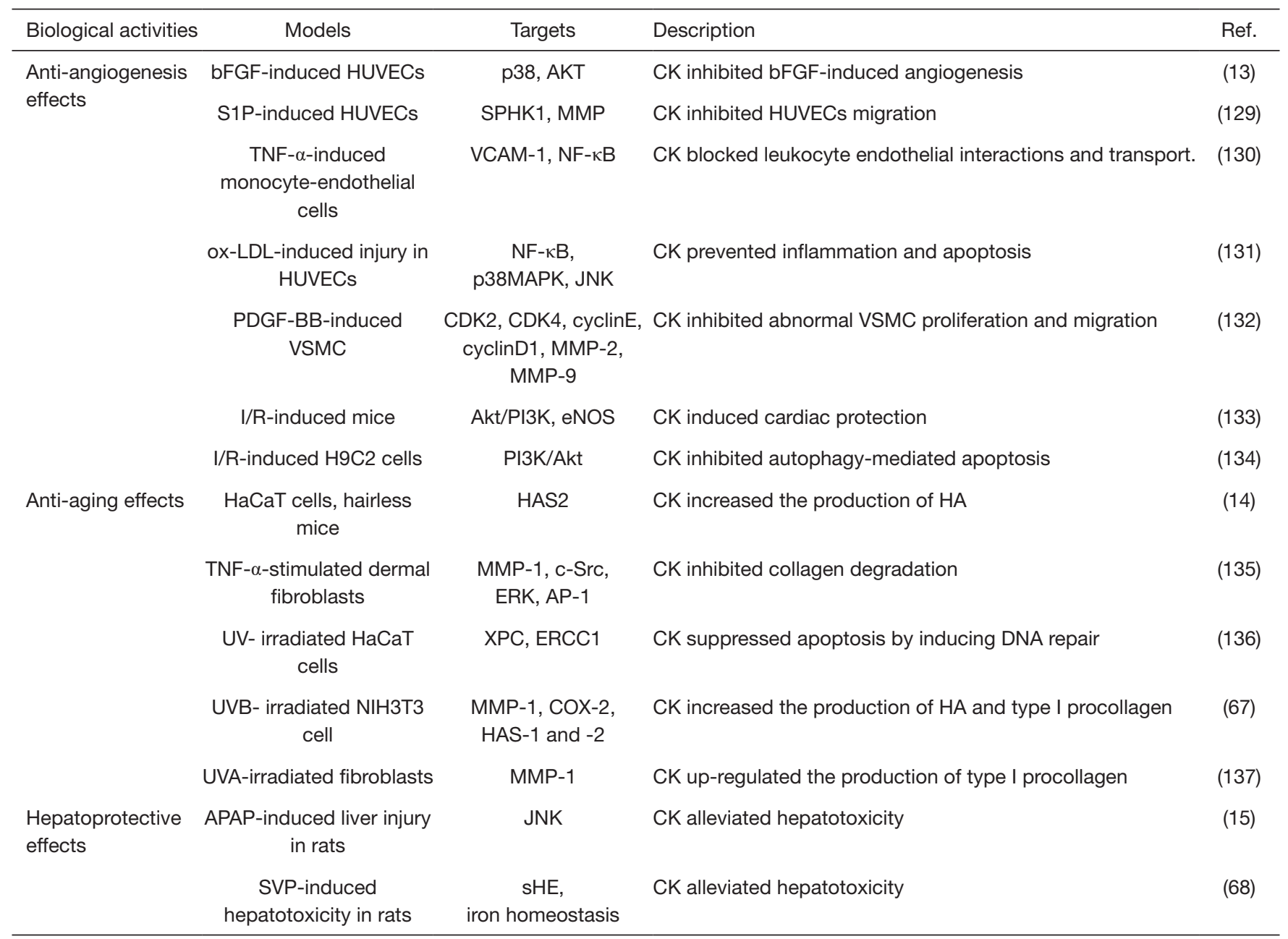

CK, Ginsenoside compound K; TNF, tumor necrosis factor; iNOS, inducible nitric-oxide synthase; COX-2, cyclooxygenase; AKT, Serine/ threonine protein kinase; IRAK, interleukin-1 receptor-related kinase; IKK- $\beta$, inhibitor of nuclear factor kappa-B kinase; TLR, toll like receptor; CCL, CC chemokine ligand; CCR7, chemokine receptor; AP2, adaptor protein 2; LPS, lipopolysaccharide; IL, interleukin; IFN, interferon; $\mathrm{G} \alpha_{i}$, guanine nucleotide-binding protein subunit alpha; TCR, T cell receptor; CTLA-4, cytotoxic T-lymphocyte-associated protein 4; CD28, cluster of differentiation 28; PD-1, programmed cell death protein 1; TNFR 2, tumor necrosis factor receptor; GR, glucocorticoid receptor; FLS, fibroblast-like synovial; PXR, progesterone X receptor; GLUT2, glucose transporter protein 2; PEPCK, phosphoenolpyruvate carboxy kinase; G6Pase, glucose 6-phosphatase; ER stress, endoplasmic reticulum stress; NLRP3, NOD-like receptors; GLP-1, glucagonlike peptide-1; TGR5, G protein-coupled receptor 5; Nrf2, nuclear factor E2-related factor 2; Keap1, Keleh-like ECH-associated protein I; GABA, gamma-aminobutyric acid; 5-HT, serotonin; GABAAR, gamma-aminobutyric acid-A receptor; S1P, sphingosine-1-phosphate; Ox-LDL, oxidized low density lipoprotein; PDGF-BB, platelet-derived growth factor; SPHK1, sphingosine kinase 1; VCAM-1, vascular cell adhesion molecule 1; HA, hyaluronic acid; HAS, hyaluronic acid synthase; XPC, Xeroderma pigmentosum-C; ERCC1, excision repair cross-complementation group 1; APAP, acetaminophen; SVP, sodium valproate.

\section{Cytotoxicity of CK}

Studies have been conducted to investigate the cytotoxicity of CK against mouse high-metastatic melanoma (B16BL6), human hepatoma (HepG2), human myeloid leukemia (K562), human high-metastasis lung carcinoma (95-D), human leukemia (HL-60), and human colon cancer cell lines $(9,41,80)$. The mean concentrations of CK that inhibited cell proliferation by $50 \%\left(I C_{50}\right)$ were $12.7,11.4$, $8.5,9.7,14$, and $32 \mu \mathrm{mol} / \mathrm{L}$, respectively, and the effect was time-dependent $(9,41,80)$. 
The anti-proliferative effects of CK

In another experiment, CK exhibited significant antiproliferative effects against human colorectal cancer cell lines (HCT-116 and SW-480) at concentrations of $30-50 \mu \mathrm{M}$, indicating that it might be an effective anti-carcinogenic medicine (83). Similarly, the antiproliferative effects of $\mathrm{CK}$ on human and animal tumor cell lines have been demonstrated in many studies $(9,41,80)$. Furthermore, CK significantly induced cell cycle arrest during the G1 phase in non-small cell lung cancer cells (A549, H1975) (69), human colorectal cancer cells (HCT-116, HT-29) $(75,77,81)$, glioblastoma cells (U87MG, U373MG) (84), human glioblastoma cells (U251 MG, U87-MG) (86), human monocytes (U937) (140), and acute myeloid leukemia cells (93), which was dose- and/ or time-dependent. The major regulatory targets of CK were found to be cyclin-dependent inhibitors, including p21, p27, p15, and cyclin D $(75,77,81)$. Furthermore, CK blocked the cell cycle at the G2 phase in human gastric cancer cells (BGC823 and SGC7901) to exert an antiproliferative effect (89).

\section{The apoptotic effects of CK}

Apoptosis was shown to be significantly induced by CK in A549 (69), H1975 (69), and HL-60 (9) cell lines, human colorectal cancer cells (HCT-116, HT-29) (75-78,80-82), glioblastoma cells (U87MG, U373MG) (84), human glioblastoma cells (U251 MG, U87-MG) (86), human monocytes (U937) (140), acute myeloid leukemia cells (93), human gastric cancer cells (BGC823 and SGC7901) (89), human hepatocellular carcinoma (HCC) cells (MHCC97-H) (72), and bladder cancer cells (T24) (92).

It was also shown to induce apoptosis in cancer cells via a caspase-dependent pathway at a concentration that had low toxicity to normal cells (72). The induction of apoptosis in HT-29 and HCT-116 cells by CK was mediated by mitochondrial-dependent and caspase-dependent mechanisms via the generation of reactive oxygen species (ROS), and the mitogen-activated protein kinase (MAPK), the calmodulin-activated protein kinase/adenosine monophosphate protein kinase (AMPK) pathway, and the tumor necrosis factor (TNF)-related apoptosis-inducing ligand-mediated death receptor pathways $(76,78,80,82)$. The transcriptional activation of multiple tumor-promoting pathways in CRC was inhibited by CK, indicating that it might prevent or treat CRC (77). Morphological changes were induced in HL-60 cells by CK, leading to cell apoptosis, as indicated by typical characteristics such as
DNA fragmentation (9).

Autophagy leads to cell adaptation, cell survival, or cell death (87). The regulation of autophagy is increasingly being regarded as a promising cancer treatment (87). A study showed that CK induced the ROS-mediated inhibition of autophagy flux, which inhibited the proliferation of neuroblastoma cells and promoted cell apoptosis (87). In non-small cell lung cancer cells (A549, H1975), CK promoted autophagy to induce cell apoptosis through the AMPK-mTOR and c-Jun N-terminal kinase (JNK) signaling pathways (69). In addition, CK induced the apoptosis of colon cancer cell lines (HT-29, HCT-116) through autophagy via ROS production and JNK activation (76,78).

\section{Inhibition of tumor cell invasion and metastasis by CK}

The invasion and metastasis of tumor cells are important for the prognosis of cancer patients and are therapeutic targets of tumor therapy. CK Significant reductions in the colony formation, adhesion, and invasion of HCC cells were exerted by $\mathrm{CK}$ in vitro, and it inhibited metastasis and growth of HCC in vivo related to the nuclear export of nuclear factorkappa B (NF- $\mathrm{B}$ ) p65 nuclear export and the reduction of metalloproteinase 2/9 (MMP-2/9) expression (73). It was also shown that CK reduced glioblastoma cell markers (CD133, Nanog, Oct4, and Sox2) to inhibit their growth, metastasis, and invasion potential (84). The migration and invasiveness of C6 glioma and astroglioma cells was inhibited by CK, suggesting it might control the growth and invasiveness of brain tumors $(85,88)$. Osteosarcoma is a malignant bone tumor, and CK was shown to inhibit the migration and invasion of osteosarcoma cells via the PI3K/ mTOR/p70S6K1 signaling pathway (90).

\section{Myelosuppression of CK}

In a study of the effects of CK on myelosuppression in mice induced by cyclophosphamide (CTX), CK could increase the thymus index, the yields of colony formation units-granulocyte monocyte and colony formation unitsmegakaryocytic. CK could control apoptosis and promote cells to enter the normal cell cycle by the bcl-2/bax signaling pathway and MEK/ERK signaling pathway. It suggested that CK can improve the hematopoietic function of myelosuppression among mice (141).

\section{Anti-inflammatory and anti-allergic effects of CK}

Inflammation, including the sustained production of 
nitric oxide (NO) and prostaglandins (PGs), is important in the pathophysiological changes of rheumatic diseases and other inflammatory diseases (142). Recent studies have shown that the anti-inflammatory activities of CK on lipopolysaccharide (LPS)-induced mononuclear macrophages (RAW264.7), and reported that CK downregulated inducible nitric-oxide synthase (iNOS) levels, ROS, and cyclooxygenase-2 proteins by inhibiting nuclear factor- $\kappa \mathrm{B}(\mathrm{NF}-\kappa \mathrm{B})$ and MAPK activation, which suppressed $\mathrm{NO}$ and prostaglandin E2 (PGE2) production $\left(I C_{50}=0.012\right.$ and $0.004 \mathrm{mM}$, respectively) $(11,143)$. It also could inhibit the migration of RAW264.7 by blocking the activation of NF- $\kappa \mathrm{B}$ and up-regulating the expression of PPAR $\gamma$ and, indicating that CK could inhibit the activation of inflammatory macrophages and increase the expression of anti-inflammatory macrophages (144). It had a negative regulatory effect on the production of proinflammatory cytokines, and the activation of inflammatory pathways in LPS- or zymosan-induced mononuclear macrophages at non-cytotoxic concentrations, indicating that $\mathrm{CK}$ is involved in the regulation of inflammation (96-99). When administered in vivo, CK inhibited the production of systemic inflammatory cytokines and reduced the mortality rate of inflammatory shock in mice (99). Therefore, CK might control excessive lethal inflammation (96-99).

In a collagen-induced arthritis (CIA) model, CK inhibited the abnormal activation and differentiation of $\mathrm{T}$ cells and $\mathrm{B}$ cells and improved the outcome of CIA by reducing the proportion of M1 and M2 macrophages (100-102). C-K could promote TLR4-Gas coupling and inhibit TLR4-Gai coupling through $\beta$-arrestin2 regulation in macrophages, leading to the function inhibition of immune cells including macrophage polarization and phagocytosis (102). Several studies using complete Freund's adjuvant-induced adjuvantarthritis rats models have reported that CK reduced disease severity, foot-pad swelling, and the degree of pathology in the joints by inhibiting the proliferation of $\mathrm{B}$ cells, $\mathrm{T}$ cells, and fibroblast-like synoviocytes, and the level of autoantibodies, macrophage phagocytosis, and the secretion of proinflammatory cytokines (104-107).

Other studies using dextran sodium sulfateinduced colitis mouse models showed that CK relieved histopathological injury in mild and severe colitis. In these studies, CK targeted the progesterone $\mathrm{X}$ receptor (PXR)/NF- $\mathrm{\kappa B}$ interactions to improve myeloperoxidase (MPO) activity, reduce the production of proinflammatory cytokines (TNF- $\alpha$, IL-1 $\beta$, and IL- 6 ), and increase the antiinflammatory cytokines $(108,109)$. In addition, CK also could as a drug candidate for IgA nephropathy through inhibiting the activation of NLRP3 inflammasome in renal tissues, macrophages and bone marrow-derived dendritic cells, enhancing the induction of autophagy through increased SIRT1 expression, and eliciting autophagymediated NLRP3 inflammasome inhibition (145).

\section{Anti-diabetic effects of $C K$}

Diabetes mellitus, caused by a deficiency in insulin secretion and action, often leads to chronic progressive disease, functional decline, and failure of multiple tissues and organs due to metabolic disorders (146). At present, there are no effective drugs to treat diabetes. Current treatments focus on stimulating insulin production, increasing the sensitivity of peripheral tissues to insulin, and inhibiting liver glucose output using insulin-like preparations (146). Importantly, CK also promotes these functions.

In vitro studies using HIT-T15 cells and primary cultured islet cells have shown that CK enhances insulin secretion in a dose-dependent manner, which may be related to adenosine triphosphate (ATP)-sensitive $\mathrm{K}^{+}$channels (10). Similar to sulfonylurea, CK stimulated insulin secretion and enhanced the anti-diabetic effect of metformin in $\mathrm{db} /$ $\mathrm{db}$ mice. Thus, CK has potential applications for diabetic therapy when used in combination with sulfonylurea (112). A study using MIN6 pancreatic $\beta$-cells reported that CK significantly enhanced insulin secretion by up-regulating the expression of glucose transporter protein $2(113,117)$.

In a long-term study of $\mathrm{db} / \mathrm{db}$ mice, $\mathrm{CK}$ enhanced plasma adiponectin production, changed glucose metabolism in the liver from glucose production to glucose utilization, which improved insulin sensitivity, induced hypoglycemic effects, and improved glucose tolerance (10). After feeding diabetic model mice with CK $30 \mathrm{mg} / \mathrm{kg} /$ day for 4 weeks, hypoglycemic and insulin sensitivity of type 2 diabetes was improved by reducing phosphoenolpyruvate carboxy kinase and glucose 6-phosphatase expression in the liver (114). Hyperglycemia and insulin resistance in diabetic rats was improved by CK via enhancement of insulin sensitivity and insulin signaling and inhibiting inflammation $(115,117)$.

Anti-diabetic effects were induced by CK by reducing the expression of key gluconeogenic enzymes in the liver and hepatic gluconeogenesis was inhibited by enhancement of AMPK activity (116). Furthermore, CK promoted the uptake of glucose by adipocytes, indicating it might have hypoglycemic properties and insulin-like activity, which is important for its potential used in diabetes (118). Treatment 
with CK prevented pancreatic islet destruction and retained more insulin in $\mathrm{db} / \mathrm{db}$ mice (10). These anti-diabetes effects of CK were mediated by inhibiting the AMPK-JNK pathway and preventing apoptosis of pancreatic islet cells in vitro and in vivo (119).

Glucagon-like peptide- 1 inhibits pancreatic $\beta$-cell apoptosis and stimulates glucose-stimulated insulin secretion (147). Studies showed that CK induced hypoglycemic effects by stimulating the secretion of glucagon-like peptide-1 in NCI-H716 cells via bile acid receptor activation (120) (125) and protected against diabetic nephropathy by inhibiting NLRP3 inflammasome activation and NF- $\mathrm{NB} / \mathrm{p} 38$ signaling pathway $(121,126)$.

\section{Effects of CK on the CNS}

Many studies have reported that CK improves the cognition of neurological diseases, has a neuroprotective effect (122), and protects neurotransmission (27).

\section{Cognition and neuroprotection effects of CK}

Amyloid- $\beta$ (A $\beta)$ peptide is a biomarker of Alzheimer's disease (AD) (148). It has been shown that CK promotes the clearance of $\mathrm{A} \beta$ by enhancing autophagy in primary astrocytes and improves memory in scopolamine hydrobromide-injured mice by inhibiting $\mathrm{A} \beta$ accumulation and activating the Nrf2/Keap1 signaling pathway (123). In addition, CK reduced oxidative damage to neurons and inhibited neuron apoptosis (65). In a slow cerebral hypoperfusion $(\mathrm{CCH})$ rat model, $\mathrm{CK}$ inhibited $\mathrm{CCH}-$ induced neuron injury and $\mathrm{A} \beta$ accumulation. Furthermore, CK attenuated cognitive deficits in vascular dementia rats (122). When HT22 cells were incubated with CK and exposed to $A \beta$, neuronal damage caused by $A \beta$ was inhibited by activating the energy metabolism signaling pathway (124). Therefore, CK might be a useful preventive or therapeutic agent for $\mathrm{AD}(65,122-124)$. When treating nervous system disease, chemotherapy often leads to neurocognitive impairment, including learning and memory. Thus, permanently repairing and improving cognitive impairment are important for the patient (149). Treatment with $10 \mathrm{mg} / \mathrm{kg}$ CK alleviated the reduction of hippocampal neurogenesis caused by cyclophosphamide indicating CK might improve or repair the side-effects caused by chemotherapy agents $(108,112,131,149)$.

Microglia activation is important in the pathogenesis of various neurological diseases. The anti-inflammatory and neuroprotective effects of CK have been demonstrated in brain disease models of sepsis (systemic inflammation) and brain ischemia in mice. It was shown to reduce the infarct volume of ischemic brains induced by middle cerebral artery occlusion and suppress microglial activation in the ischemic cortex as well as inhibiting the activities of ROS, MAPKs, and NF- $\mathrm{KB}$ /activator protein to suppress microglial activation in LPS-induced BV2 cells and primary cultured microglial cells (16). The expressions of brainderived neurotrophic factor and nerve growth factor were increased in rats treated with $\mathrm{CK}$, indicating that it promotes neurotrophic protection of the CNS (125).

The proliferation and differentiation of Schwann cells are critical for the remyelination of injured peripheral nerve. It was shown that CK induced cell proliferation, migration and differentiation via the activation of MEK/ERK1/2 and PI3K/AKT pathways in cultured primary Schwann cells $(133,150)$.

\section{Neurotransmission modulation by CK}

At a dose of $10 \mu \mathrm{mol} / \mathrm{L}, \mathrm{CK}$ increased the spontaneous release of gamma-aminobutyric acid (GABA) by promoting the release of $\mathrm{Ca}^{2+}$ from presynaptic $\mathrm{Ca}^{2+}$ stores and inhibited the transmission of hippocampal CA3 pyramidal neurons in rats and the physiological functions mediated by the hippocampus (27). It also inhibited GABA-induced inward peak current $\left(I_{G A B A}\right)$ by inhibiting GABA receptor ${ }_{\mathrm{C}}$ $\left(\mathrm{GABA}_{\mathrm{C}}\right)\left(I C_{50}\right.$ value of $\left.52.1 \pm 2.3 \mu \mathrm{mol} / \mathrm{L}\right)(126)$. This suggests that $\mathrm{CK}$ may regulate $\mathrm{GABA}_{\mathrm{C}}$ receptor channel activity in the brain. An imbalance between GABAmediated inhibition and glutamate-mediated excitation is a major pathological mechanism of epilepsy and therefore GABA and glutamate neurotransmission have become important targets for epilepsy control (127). By promoting the release of GABA in the hippocampus and enhancing GABA-mediated inhibitory synaptic transmission, CK exerted an antiepileptic effect.

Yamada et al. (128) found that CK had a beneficial effect in a mouse model of depression-like state induced by ovariectomy by preventing postoperative prolonged fixation, which was mediated by the serotonin (5-HT) receptor in a dose-dependent manner. Song et al. (125) established a chronic unpredictable mild stress model in rats, and found that CK alleviated depression-like behavior, increased the levels of 5-HT, dopamine, and their metabolites in the prefrontal cortex and hippocampus, and reversed monoamine oxidase B overexpression in the prefrontal cortex and hippocampus. These results suggest CK has an antidepressant effect in rodents, which is related to the 
regulation of monoamine neurotransmitter concentrations.

\section{Anti-angiogenesis effects of $C K$}

Few studies have investigated the cardiovascular effects of CK, although it has a protective effect on vascular endothelial cells and smooth muscle cells $(13,132)$.

It has been shown that $\mathrm{CK}$ attenuates the expression of cyclin D1 and significantly inhibits the proliferation, migration, and lumen formation of basic fibroblast growth factor (bFGF)-induced human umbilical vein endothelial cells (HUVECs), and prevents bFGF-induced angiogenesis in mice $(13,129)$.

The adhesion of leukocytes to endothelial cells and leukocyte transport are involved in the early stage of atherosclerosis (130). Anti-atherogenic effects were exerted by $\mathrm{CK}$ by negatively regulating $\mathrm{NF}-\kappa \mathrm{B}$ signaling and blocking leukocytes transport by inhibiting interactions between leukocytes and endothelial cells (130). It also reduced HUVEC inflammation and apoptosis induced by oxidized low-density lipoprotein by inhibiting the nuclear translocation of NF- $\mathrm{KB}$ and phosphorylation of p38MAPK and JNK (131). Furthermore, CK significantly inhibited the proliferation of vascular smooth muscle cells stimulated by platelet-derived growth factor BB in vitro by a dosedependent mechanism involving the blockade of cells in the G1 phase (132). Formation of the angiogenic intima was significantly inhibited in vivo by CK indicating it might be a candidate therapeutic agent for atherosclerosis (132).

In a mouse model of myocardial ischemia-reperfusion (I/R) injury, CK protected the myocardium, reduced the infarct area, and inhibited myocardial cell apoptosis, indicating that it has a protective effect on the heart damaged caused by I/R $(133,134)$.

\section{Anti-aging effects of $C K$}

The local application of CK to the skin of hairless mice increased the hyaluronic acid content in the epidermis and papillary dermis by up-regulating hyaluronic acid synthase 2 (14). Therefore, the local use of CK may prevent or improve xerosis and wrinkles in the skin (14). It suppressed MMP-1 secretion and increased type I procollagen secretion in TNF- $\alpha$-stimulated human skin fibroblasts (HS68 cells), which inhibited collagen degradation in human fibroblasts (135). It also down-regulated MMP1 activity, cyclooxygenase- 2 production, and restored the production of type I collagen in ultraviolet (UV) A/UVB- irradiated fibroblasts and protected UV-irradiated $\mathrm{HaCaT}$ cells from apoptosis by inducing DNA repair $(67,136,137)$. These studies indicate that CK has anti-aging and hydrating effects and could be used in cosmetic products to protect skin from UV and increase skin moisture levels (137).

\section{Hepatoprotective effects of CK}

Studies have shown that CK has hepatoprotective activity. It inhibited liver injury induced by acetaminophen in vivo and significantly reduced aspartic aminotransferase and alanine aminotransferase concentrations by inhibiting JNK signaling in HepG2 cells (15). It also significantly reversed liver injury induced by sodium valproate (SVP) and had a marked hepatoprotective effect on SVP-induced hepatotoxicity via antioxidant effects including regulation of the peroxisome pathway, downregulating soluble epoxide hydrolase (sHE, UniProt ID P80299) and regulating iron homeostasis dependent on hepcidin upregulation (68).

\section{Conclusions}

As rare ginsenoside, CK does not exist in natural ginsenoside but can be produced effectively with the advent of modern enzyme technology. It is generally agreed that compound $\mathrm{K}$ is more bioavailable than the parent ginsenosides, including $\mathrm{Rb} 1, \mathrm{Rb} 2$, and $\mathrm{Rc}$, and is the major contributing factor to the health benefits of ginseng. It has a wide range of pharmacological functions, especially anticancer effects. The application of CK provides a new perspective for the development of anticancer agents. Similarly, CK has important roles in many physiological processes and could be used as a preventive or therapeutic agent for various diseases.

Although it is possible that new mechanisms not mentioned in this article in the foreseeable future, many mechanisms of CK remain unknown. Firstly, most of understanding of various systemic diseases pharmacological effects of CK and its precursor are derived from animal and cell models, the results cannot be directly translated to the healthy normal population, further experiment verification about human in vitro are necessary. Secondly, more experiments need to be carried out to corroborate the specific role of CK in related systemic diseases and related mechanisms. Thirdly, further clinical trials are requirement for investigating the safety and efficacy of CK. Fourthly, ginseng and ginsenosides have been proved to have a variety of pharmacological effects, further research is required to 
establish whether $\mathrm{CK}$ is the major component of ginseng responsible for its pharmacological activities.

In conclusion, we need to carry out more studies to improve the relevant mechanisms of CK, so as to better provide help for the clinical application of CK.

\section{Acknowledgments}

Funding: This work was supported by the Chengdu Science and Technology Bureau Technology Innovation R\&D Project (grant No. 2021-YF05-00595-5N).

\section{Footnote}

Reporting Checklist: The authors have completed the Narrative Review reporting checklist. Available at https:// atm.amegroups.com/article/view/10.21037/atm-22-501/rc

Conflicts of Interest: All authors have completed the ICMJE uniform disclosure form (available at https://atm. amegroups.com/article/view/10.21037/atm-22-501/coif). All authors report the study was supported by Chengdu Science and Technology Bureau Technology Innovation R\&D Project (grant No. 2021-YF05-00595-5N). The authors have no other conflicts of interest to declare.

Ethical Statement: The authors are accountable for all aspects of the work in ensuring that questions related to the accuracy or integrity of any part of the work are appropriately investigated and resolved.

Open Access Statement: This is an Open Access article distributed in accordance with the Creative Commons Attribution-NonCommercial-NoDerivs 4.0 International License (CC BY-NC-ND 4.0), which permits the noncommercial replication and distribution of the article with the strict proviso that no changes or edits are made and the original work is properly cited (including links to both the formal publication through the relevant DOI and the license). See: https://creativecommons.org/licenses/by-nc-nd/4.0/.

\section{References}

1. Liu L, Xu FR, Wang YZ. Traditional uses, chemical diversity and biological activities of Panax L. (Araliaceae): A review. J Ethnopharmacol 2020;263:112792.

2. Li D, Wu Y, Zhang C, et al. Production of Triterpene Ginsenoside Compound $\mathrm{K}$ in the Non-conventional Yeast
Yarrowia lipolytica. J Agric Food Chem 2019;67:2581-8.

3. Christensen LP. Ginsenosides chemistry, biosynthesis, analysis, and potential health effects. Adv Food Nutr Res 2009;55:1-99.

4. Yang Y, Liu X, Li S, et al. Genome-scale CRISPR screening for potential targets of ginsenoside compound $\mathrm{K}$. Cell Death Dis 2020;11:39.

5. Jin S, Jeon JH, Lee S, et al. Detection of 13 Ginsenosides (Rb1, Rb2, Rc, Rd, Re, Rf, Rg1, Rg3, Rh2, F1, Compound K, 20(S)-Protopanaxadiol, and 20(S)-Protopanaxatriol) in Human Plasma and Application of the Analytical Method to Human Pharmacokinetic Studies Following Two Week-Repeated Administration of Red Ginseng Extract. Molecules 2019;24:2618.

6. Fukami H, Ueda T, Matsuoka N. Pharmacokinetic Study of Compound $\mathrm{K}$ in Japanese Subjects After Ingestion of Panax ginseng Fermented by Lactobacillus paracasei A221 Reveals Significant Increase of Absorption into Blood. J Med Food 2019;22:257-63.

7. Xie T, Li Z, Li B, et al. Characterization of ginsenoside compound $\mathrm{K}$ metabolites in rat urine and feces by ultraperformance liquid chromatography with electrospray ionization quadrupole time-of-flight tandem mass spectrometry. Biomed Chromatogr 2019;33:e4643.

8. Kim MJ, Upadhyaya J, Yoon MS, et al. Highly regioselective biotransformation of ginsenoside $\mathrm{Rb} 2$ into compound $\mathrm{Y}$ and compound $\mathrm{K}$ by $\beta$-glycosidase purified from Armillaria mellea mycelia. J Ginseng Res 2018;42:504-11.

9. Cho SH, Chung KS, Choi JH, et al. Compound K, a metabolite of ginseng saponin, induces apoptosis via caspase-8-dependent pathway in HL-60 human leukemia cells. BMC Cancer 2009;9:449.

10. Han GC, Ko SK, Sung JH, et al. Compound K enhances insulin secretion with beneficial metabolic effects in $\mathrm{db} / \mathrm{db}$ mice. J Agric Food Chem 2007;55:10641-8.

11. Park EK, Shin YW, Lee HU, et al. Inhibitory effect of ginsenoside $\mathrm{Rb} 1$ and compound $\mathrm{K}$ on $\mathrm{NO}$ and prostaglandin E2 biosyntheses of RAW264.7 cells induced by lipopolysaccharide. Biol Pharm Bull 2005;28:652-6.

12. Shin YW, Bae EA, Kim SS, et al. Effect of ginsenoside Rb1 and compound $\mathrm{K}$ in chronic oxazolone-induced mouse dermatitis. Int Immunopharmacol 2005;5:1183-91.

13. Jeong A, Lee HJ, Jeong SJ, et al. Compound K inhibits basic fibroblast growth factor-induced angiogenesis via regulation of $\mathrm{p} 38$ mitogen activated protein kinase and AKT in human umbilical vein endothelial cells. Biol Pharm Bull 2010;33:945-50. 
14. Kim S, Kang BY, Cho SY, et al. Compound K induces expression of hyaluronan synthase 2 gene in transformed human keratinocytes and increases hyaluronan in hairless mouse skin. Biochem Biophys Res Commun 2004;316:348-55.

15. Igami K, Shimojo Y, Ito H, et al. Hepatoprotective effect of fermented ginseng and its major constituent compound $\mathrm{K}$ in a rat model of paracetamol (acetaminophen)-induced liver injury. J Pharm Pharmacol 2015;67:565-72.

16. Park JS, Shin JA, Jung JS, et al. Anti-inflammatory mechanism of compound $\mathrm{K}$ in activated microglia and its neuroprotective effect on experimental stroke in mice. J Pharmacol Exp Ther 2012;341:59-67.

17. Jia L, Zhao Y, Liang XJ. Current evaluation of the millennium phytomedicine- ginseng (II): Collected chemical entities, modern pharmacology, and clinical applications emanated from traditional Chinese medicine. Curr Med Chem 2009;16:2924-42.

18. Yu H, Zhang C, Lu M, et al. Purification and characterization of new special ginsenosidase hydrolyzing multi-glycisides of protopanaxadiol ginsenosides, ginsenosidase type I. Chem Pharm Bull (Tokyo) 2007;55:231-5.

19. Yosioka I, Sugawara T, Imai K, et al. Soil Bacterial Hydrolysis leading to Genuine Aglycone. V. On Ginsenosides-Rb_1,Rb_2, and Rc of the Ginseng Root Saponins. Chemical \& Pharmaceutical Bulletin 1972:2450-3.

20. Karikura M, Miyase T, Tanizawa H, et al. Studies on absorption, distribution, excretion and metabolism of ginseng saponins. $\mathrm{V}$. The decomposition products of ginsenoside $\mathrm{Rb} 2$ in the large intestine of rats. Chem Pharm Bull (Tokyo) 1990;38:2859-61.

21. Karikura M, Miyase T, Tanizawa H, et al. Studies on absorption, distribution, excretion and metabolism of ginseng saponins. VII. Comparison of the decomposition modes of ginsenoside- $\mathrm{Rb} 1$ and $-\mathrm{Rb} 2$ in the digestive tract of rats. Chem Pharm Bull (Tokyo) 1991;39:2357-61.

22. Hasegawa H, Sung JH, Matsumiya S, et al. Main ginseng saponin metabolites formed by intestinal bacteria. Planta Med 1996;62:453-7.

23. Hasegawa H, Sung JH, Benno Y. Role of human intestinal Prevotella oris in hydrolyzing ginseng saponins. Planta Med 1997;63:436-40.

24. Bae EA, Park SY, Kim DH. Constitutive beta-glucosidases hydrolyzing ginsenoside Rb1 and Rb2 from human intestinal bacteria. Biol Pharm Bull 2000;23:1481-5.

25. Akao T, Kanaoka M, Kobashi K. Appearance of compound
$\mathrm{K}$, a major metabolite of ginsenoside $\mathrm{Rb} 1$ by intestinal bacteria, in rat plasma after oral administration-measurement of compound $\mathrm{K}$ by enzyme immunoassay. Biol Pharm Bull 1998;21:245-9.

26. Akao T, Kida H, Kanaoka M, et al. Intestinal bacterial hydrolysis is required for the appearance of compound $\mathrm{K}$ in rat plasma after oral administration of ginsenoside $\mathrm{Rb} 1$ from Panax ginseng. J Pharm Pharmacol 1998;50:1155-60.

27. Bae MY, Cho JH, Choi IS, et al. Compound K, a metabolite of ginsenosides, facilitates spontaneous GABA release onto CA3 pyramidal neurons. J Neurochem 2010;114:1085-96.

28. Takino Y. Studies on the pharmacodynamics of ginsenoside-Rg1, -Rb1 and -Rb2 in rats. Yakugaku Zasshi 1994;114:550-64.

29. Xu QF, Fang XL, Chen DF. Pharmacokinetics and bioavailability of ginsenoside $\mathrm{Rb} 1$ and $\mathrm{Rg} 1$ from Panax notoginseng in rats. J Ethnopharmacol 2003;84:187-92.

30. Chi H, Kim DH, Ji GE. Transformation of ginsenosides $\mathrm{Rb} 2$ and Rc from Panax ginseng by food microorganisms. Biol Pharm Bull 2005;28:2102-5.

31. Chi H, Ji GE. Transformation of ginsenosides Rb1 and Re from Panax ginseng by food microorganisms. Biotechnol Lett 2005;27:765-71.

32. Bae EA, Choo MK, Park EK, et al. Metabolism of ginsenoside $\mathrm{R}(\mathrm{c})$ by human intestinal bacteria and its related antiallergic activity. Biol Pharm Bull 2002;25:743-7.

33. Hou JG, Xue JJ, Sun MQ, et al. Highly selective microbial transformation of major ginsenoside Rb1 to gypenoside LXXV by Esteya vermicola CNU120806. J Appl Microbiol 2012;113:807-14.

34. Zhou W, Yan Q, Li JY, et al. Biotransformation of Panax notoginseng saponins into ginsenoside compound $\mathrm{K}$ production by Paecilomyces bainier sp. 229. J Appl Microbiol 2008;104:699-706.

35. Han Y, Sun B, Hu X, et al. Transformation of bioactive compounds by Fusarium sacchari fungus isolated from the soil-cultivated ginseng. J Agric Food Chem 2007;55:9373-9.

36. Han Y, Sun B, Jiang B, et al. Microbial transformation of ginsenosides Rb1, Rb3 and Rc by Fusarium sacchari. J Appl Microbiol 2010;109:792-8.

37. Yang Y, Wang Y, Yan M, et al. Screening of plant pathogenic fungi by ginsenoside compound $\mathrm{K}$ production. Zhongguo Zhong Yao Za Zhi 2011;36:1596-8.

38. Wu L, Jin Y, Yin C, et al. Co-transformation of Panax major ginsenosides $\mathrm{Rb}_{1}$ and $\mathrm{Rg}_{1}$ to minor ginsenosides $\mathrm{C}-\mathrm{K}$ and $\mathrm{F}_{1}$ by Cladosporium cladosporioides. J Ind Microbiol 
Biotechnol 2012;39:521-7.

39. Chen GT, Yang M, Song Y, et al. Microbial transformation of ginsenoside $\mathrm{Rb}(1)$ by Acremonium strictum. Appl Microbiol Biotechnol 2008;77:1345-50.

40. Liu CY, Zhou RX, Sun CK, et al. Preparation of minor ginsenosides C-Mc, C-Y, F2, and C-K from American ginseng $\mathrm{PPD}$-ginsenoside using special ginsenosidase type-I from Aspergillus niger g.848. J Ginseng Res 2015;39:221-9.

41. Zhou W, Feng MQ, Li JY, et al. Studies on the preparation, crystal structure and bioactivity of ginsenoside compound K. J Asian Nat Prod Res 2006;8:519-27.

42. Quan LH, Piao JY, Min JW, et al. Bioconversion of ginsenoside rb1 into compound $\mathrm{k}$ by Leuconostoc citreum LH1 isolated from kimchi. Braz J Microbiol 2011;42:1227-37.

43. Quan LH, Piao JY, Min JW, et al. Biotransformation of Ginsenoside Rb1 to Prosapogenins, Gypenoside XVII, Ginsenoside Rd, Ginsenoside F2, and Compound K by Leuconostoc mesenteroides DC102. J Ginseng Res 2011;35:344-51.

44. Quan LH, Kim YJ, Li GH, et al. Microbial transformation of ginsenoside $\mathrm{Rb} 1$ to compound $\mathrm{K}$ by Lactobacillus paralimentarius. World J Microbiol Biotechnol 2013;29:1001-7.

45. Shin KC, Choi HY, Seo MJ, et al. Improved conversion of ginsenoside $\mathrm{Rb} 1$ to compound $\mathrm{K}$ by semi-rational design of Sulfolobus solfataricus $\beta$-glycosidase. AMB Express 2017;7:186.

46. Park SY, Bae EA, Sung JH, et al. Purification and characterization of ginsenoside Rb1-metabolizing betaglucosidase from Fusobacterium K-60, a human intestinal anaerobic bacterium. Biosci Biotechnol Biochem 2001;65:1163-9.

47. Yan Q, Zhou W, Li X, et al. Purification method improvement and characterization of a novel ginsenosidehydrolyzing beta-glucosidase from Paecilomyces Bainier sp. 229. Biosci Biotechnol Biochem 2008;72:352-9.

48. Fu Y, Yin Z, Wu L, et al. Diversity of cultivable $\beta$-glycosidase-producing micro-organisms isolated from the soil of a ginseng field and their ginsenosideshydrolysing activity. Lett Appl Microbiol 2014;58:138-44.

49. Yoo MH, Yeom SJ, Park CS, et al. Production of aglycon protopanaxadiol via compound $\mathrm{K}$ by a thermostable $\beta$-glycosidase from Pyrococcus furiosus. Appl Microbiol Biotechnol 2011;89:1019-28.

50. Noh KH, Oh DK. Production of the rare ginsenosides compound $\mathrm{K}$, compound $\mathrm{Y}$, and compound $\mathrm{Mc}$ by a thermostable beta-glycosidase from Sulfolobus acidocaldarius. Biol Pharm Bull 2009;32:1830-5.

51. Noh KH, Son JW, Kim HJ, et al. Ginsenoside compound $\mathrm{K}$ production from ginseng root extract by a thermostable beta-glycosidase from Sulfolobus solfataricus. Biosci Biotechnol Biochem 2009;73:316-21.

52. Shin KC, Kim TH, Choi JH, et al. Complete Biotransformation of Protopanaxadiol-Type Ginsenosides to 20- O- $\beta$-Glucopyranosyl-20( S)-protopanaxadiol Using a Novel and Thermostable $\beta$-Glucosidase. J Agric Food Chem 2018;66:2822-9.

53. Choi JH, Shin KC, Oh DK. An L213A variant of $\beta$-glycosidase from Sulfolobus solfataricus with increased $\alpha$-L-arabinofuranosidase activity converts ginsenoside Rc to compound K. PLoS One 2018;13:e0191018.

54. Cui CH, Jeon BM, Fu Y, et al. High-density immobilization of a ginsenoside-transforming $\beta$-glucosidase for enhanced food-grade production of minor ginsenosides. Appl Microbiol Biotechnol 2019;103:7003-15.

55. Kim KA, Yoo $\mathrm{HH}, \mathrm{Gu} W$, et al. A prebiotic fiber increases the formation and subsequent absorption of compound $\mathrm{K}$ following oral administration of ginseng in rats. J Ginseng Res 2015;39:183-7.

56. Wan JY, Wang CZ, Zhang QH, et al. Significant difference in active metabolite levels of ginseng in humans consuming Asian or Western diet: The link with enteric microbiota. Biomed Chromatogr 2017.

57. Chen L, Zhou L, Wang Y, et al. Food and Sex-Related Impacts on the Pharmacokinetics of a Single-Dose of Ginsenoside Compound K in Healthy Subjects. Front Pharmacol 2017;8:636.

58. Chen L, Zhou L, Huang J, et al. Single- and MultipleDose Trials to Determine the Pharmacokinetics, Safety, Tolerability, and Sex Effect of Oral Ginsenoside Compound $\mathrm{K}$ in Healthy Chinese Volunteers. Front Pharmacol 2017;8:965.

59. Kim HK. Pharmacokinetics of ginsenoside Rb1 and its metabolite compound $\mathrm{K}$ after oral administration of Korean Red Ginseng extract. J Ginseng Res 2013;37:451-6.

60. Gao Y, Wang T, Wang G, et al. Preclinical safety of ginsenoside compound K: Acute, and 26-week oral toxicity studies in mice and rats. Food Chem Toxicol 2019;131:110578.

61. Li W, Zhang X, Ding M, et al. Genotoxicity and subchronic toxicological study of a novel ginsenoside derivative 25-OCH3-PPD in beagle dogs. J Ginseng Res 
2019;43:562-71.

62. Hou J, Xue J, Zhao X, et al. Octyl ester of ginsenoside compound $\mathrm{K}$ as novel anti-hepatoma compound: Synthesis and evaluation on murine $\mathrm{H} 22$ cells in vitro and in vivo. Chem Biol Drug Des 2018;91:951-6.

63. Yang WS, Yi YS, Kim D, et al. Nuclear factor kappa-Band activator protein-1-mediated immunostimulatory activity of compound $\mathrm{K}$ in monocytes and macrophages. J Ginseng Res 2017;41:298-306.

64. Hwang YC, Oh DH, Choi MC, et al. Compound K attenuates glucose intolerance and hepatic steatosis through AMPK-dependent pathways in type 2 diabetic OLETF rats. Korean J Intern Med 2018;33:347-55.

65. Yang Q, Lin J, Zhang H, et al. Ginsenoside Compound K Regulates Amyloid $\beta$ via the Nrf2/Keap1 Signaling Pathway in Mice with Scopolamine HydrobromideInduced Memory Impairments. J Mol Neurosci 2019;67:62-71.

66. Zhou L, Zheng Y, Li Z, et al. Compound K Attenuates the Development of Atherosclerosis in ApoE(-/-) Mice via LXR $\alpha$ Activation. Int J Mol Sci 2016;17:1054.

67. Kim E, Kim D, Yoo S, et al. The skin protective effects of compound $\mathrm{K}$, a metabolite of ginsenoside Rb1 from Panax ginseng. J Ginseng Res 2018;42:218-24.

68. Zhou L, Chen L, Zeng X, et al. Ginsenoside compound $\mathrm{K}$ alleviates sodium valproate-induced hepatotoxicity in rats via antioxidant effect, regulation of peroxisome pathway and iron homeostasis. Toxicol Appl Pharmacol 2020;386:114829.

69. Kirtonia A, Sethi G, Garg M. The multifaceted role of reactive oxygen species in tumorigenesis. Cell Mol Life Sci 2020;77:4459-83.

70. Oh JM, Kim E, Chun S. Ginsenoside Compound K Induces Ros-Mediated Apoptosis and Autophagic Inhibition in Human Neuroblastoma Cells In Vitro and In Vivo. Int J Mol Sci 2019;20:4279.

71. Wang YS, Zhu H, Li H, et al. Ginsenoside compound K inhibits nuclear factor-kappa B by targeting Annexin A2.J Ginseng Res 2019;43:452-9.

72. Chen HF, Wu LX, Li XF, et al. Ginsenoside compound K inhibits growth of lung cancer cells via HIF-1 $\alpha$-mediated glucose metabolism. Cell Mol Biol (Noisy-le-grand) 2019;65:48-52.

73. Luo H, Vong CT, Chen H, et al. Naturally occurring anticancer compounds: shining from Chinese herbal medicine. Chin Med 2019;14:48.

74. Kim H, Roh HS, Kim JE, et al. Compound K attenuates stromal cell-derived growth factor 1 (SDF-1)- induced migration of C6 glioma cells. Nutr Res Pract 2016;10:259-64.

75. Wang CZ, Zhang Z, Wan JY, et al. Protopanaxadiol, an active ginseng metabolite, significantly enhances the effects of fluorouracil on colon cancer. Nutrients 2015;7:799-814.

76. Law CK, Kwok HH, Poon PY, et al. Ginsenoside compound $\mathrm{K}$ induces apoptosis in nasopharyngeal carcinoma cells via activation of apoptosis-inducing factor. Chin Med 2014;9:11.

77. Zhang Z, Du GJ, Wang CZ, et al. Compound K, a Ginsenoside Metabolite, Inhibits Colon Cancer Growth via Multiple Pathways Including p53-p21 Interactions. Int J Mol Sci 2013;14:2980-95.

78. Zhang X, Zhang S, Sun Q, et al. Compound K Induces Endoplasmic Reticulum Stress and Apoptosis in Human Liver Cancer Cells by Regulating STAT3. Molecules 2018;23:1482.

79. Chae S, Kang KA, Chang WY, et al. Effect of compound K, a metabolite of ginseng saponin, combined with gammaray radiation in human lung cancer cells in vitro and in vivo. J Agric Food Chem 2009;57:5777-82.

80. Lee IK, Kang KA, Lim CM, et al. Compound K, a metabolite of ginseng saponin, induces mitochondriadependent and caspase-dependent apoptosis via the generation of reactive oxygen species in human colon cancer cells. Int J Mol Sci 2010;11:4916-31.

81. Wang CZ, Du GJ, Zhang Z, et al. Ginsenoside compound $\mathrm{K}$, not Rb1, possesses potential chemopreventive activities in human colorectal cancer. Int J Oncol 2012;40:1970-6.

82. Li C, Dong Y, Wang L, et al. Ginsenoside metabolite compound $\mathrm{K}$ induces apoptosis and autophagy in nonsmall cell lung cancer cells via AMPK-mTOR and JNK pathways. Biochem Cell Biol 2019;97:406-14.

83. Yao H, Wan JY, Zeng J, et al. Effects of compound K, an enteric microbiome metabolite of ginseng, in the treatment of inflammation associated colon cancer. Oncol Lett 2018;15:8339-48.

84. Kang KA, Piao MJ, Kim KC, et al. Compound K, a metabolite of ginseng saponin, inhibits colorectal cancer cell growth and induces apoptosis through inhibition of histone deacetylase activity. Int J Oncol 2013;43:1907-14.

85. Lee S, Kwon MC, Jang JP, et al. The ginsenoside metabolite compound $\mathrm{K}$ inhibits growth, migration and stemness of glioblastoma cells. Int J Oncol 2017;51:414-24.

86. Wanderi C, Kim E, Chang S, et al. Ginsenoside 20(S)Protopanaxadiol Suppresses Viability of Human Glioblastoma Cells via Down-regulation of Cell Adhesion Proteins and Cell-cycle Arrest. Anticancer Res 
2016;36:925-32.

87. Oh JM, Kim E, Chun S. Ginsenoside Compound K Induces Ros-Mediated Apoptosis and Autophagic Inhibition in Human Neuroblastoma Cells In Vitro and In Vivo. Int J Mol Sci 2019;20:4279.

88. Kim H, Roh HS, Kim JE, et al. Compound K attenuates stromal cell-derived growth factor 1 (SDF-1)induced migration of C6 glioma cells. Nutr Res Pract 2016;10:259-64.

89. Hu C, Song G, Zhang B, et al. Intestinal metabolite compound $\mathrm{K}$ of panaxoside inhibits the growth of gastric carcinoma by augmenting apoptosis via Bid-mediated mitochondrial pathway. J Cell Mol Med 2012;16:96-106.

90. Luo H, Vong CT, Chen H, et al. Naturally occurring anticancer compounds: shining from Chinese herbal medicine. Chin Med 2019;14:48.

91. Law CK, Kwok HH, Poon PY, et al. Ginsenoside compound $\mathrm{K}$ induces apoptosis in nasopharyngeal carcinoma cells via activation of apoptosis-inducing factor. Chin Med 2014;9:11.

92. Wang H, Jiang D, Liu J, et al. Compound K induces apoptosis of bladder cancer T24 cells via reactive oxygen species-mediated p38 MAPK pathway. Cancer Biother Radiopharm 2013;28:607-14.

93. Chen Y, Xu Y, Zhu Y, et al. Anti-cancer effects of ginsenoside compound $\mathrm{k}$ on pediatric acute myeloid leukemia cells. Cancer Cell Int 2013;13:24.

94. Kwak CW, Son YM, Gu MJ, et al. A Bacterial Metabolite, Compound K, Induces Programmed Necrosis in MCF-7 Cells via GSK3ß. J Microbiol Biotechnol 2015;25:1170-6.

95. Park S, Lee HJ, Jeong SJ, et al. Inhibition of JAK1/STAT3 signaling mediates compound $\mathrm{K}$-induced apoptosis in human multiple myeloma U266 cells. Food Chem Toxicol 2011;49:1367-72.

96. Cuong TT, Yang CS, Yuk JM, et al. Glucocorticoid receptor agonist compound $\mathrm{K}$ regulates Dectin-1dependent inflammatory signaling through inhibition of reactive oxygen species. Life Sci 2009;85:625-33.

97. Joh EH, Lee IA, Jung IH, et al. Ginsenoside Rb1 and its metabolite compound $\mathrm{K}$ inhibit IRAK-1 activation-the key step of inflammation. Biochem Pharmacol 2011;82:278-86.

98. Lee JO, Choi E, Shin KK, et al. Compound K, a ginsenoside metabolite, plays an antiinflammatory role in macrophages by targeting the AKT1-mediated signaling pathway. J Ginseng Res 2019;43:154-60.

99. Yang CS, Ko SR, Cho BG, et al. The ginsenoside metabolite compound $\mathrm{K}$, a novel agonist of glucocorticoid receptor, induces tolerance to endotoxin-induced lethal shock. J Cell Mol Med 2008;12:1739-53.

100. Chen J, Wu H, Wang Q, et al. Ginsenoside metabolite compound $\mathrm{K}$ suppresses T-cell priming via modulation of dendritic cell trafficking and costimulatory signals, resulting in alleviation of collagen-induced arthritis. J Pharmacol Exp Ther 2015;353:71-9.

101.Zhang M, Hu S, Tao J, et al. Ginsenoside compound-K inhibits the activity of $\mathrm{B}$ cells through inducing $\operatorname{IgD}-\mathrm{B}$ cell receptor endocytosis in mice with collagen-induced arthritis. Inflammopharmacology 2019;27:845-56.

102. Wang R, Zhang M, Hu S, et al. Ginsenoside metabolite compound-K regulates macrophage function through inhibition of $\beta$-arrestin2. Biomed Pharmacother 2019;115:108909.

103.Liu KK, Wang QT, Yang SM, et al. Ginsenoside compound $\mathrm{K}$ suppresses the abnormal activation of $\mathrm{T}$ lymphocytes in mice with collagen-induced arthritis. Acta Pharmacol Sin 2014;35:599-612.

104.Chen J, Wang Q, Wu H, et al. The ginsenoside metabolite compound $\mathrm{K}$ exerts its anti-inflammatory activity by downregulating memory $\mathrm{B}$ cell in adjuvant-induced arthritis. Pharm Biol 2016;54:1280-8.

105. Wang Y, Chen J, Luo X, et al. Ginsenoside metabolite compound $\mathrm{K}$ exerts joint-protective effect by interfering with synoviocyte function mediated by TNF- $\alpha$ and Tumor necrosis factor receptor type 2. Eur J Pharmacol 2016;771:48-55.

106. Chen J, Wu H, Wang Q, et al. Ginsenoside metabolite compound $\mathrm{k}$ alleviates adjuvant-induced arthritis by suppressing $T$ cell activation. Inflammation 2014;37:1608-15.

107. Wu H, Chen J, Wang Q, et al. Ginsenoside metabolite compound $\mathrm{K}$ attenuates inflammatory responses of adjuvant-induced arthritis rats. Immunopharmacol Immunotoxicol 2014;36:124-9.

108.Zhang J, Cao L, Wang H, et al. Ginsenosides Regulate PXR/NF- $\kappa$ B Signaling and Attenuate Dextran Sulfate Sodium-Induced Colitis. Drug Metab Dispos 2015;43:1181-9.

109. Li J, Zhong W, Wang W, et al. Ginsenoside metabolite compound $\mathrm{K}$ promotes recovery of dextran sulfate sodiuminduced colitis and inhibits inflammatory responses by suppressing NF- $\kappa$ B activation. PLoS One 2014;9:e87810.

110. Fan H, Wang Y, Zhang X, et al. Ginsenoside compound $\mathrm{K}$ ameliorates imiquimod-induced psoriasis-like dermatitis through inhibiting REG3A/RegIII $\gamma$ expression in keratinocytes. Biochem Biophys Res Commun 
2019;515:665-71.

111. Choi K, Kim M, Ryu J, et al. Ginsenosides compound K and $\mathrm{Rh}(2)$ inhibit tumor necrosis factor-alpha-induced activation of the NF-kappaB and JNK pathways in human astroglial cells. Neurosci Lett 2007;421:37-41.

112. Yoon SH, Han EJ, Sung JH, et al. Anti-diabetic effects of compound $\mathrm{K}$ versus metformin versus compound K-metformin combination therapy in diabetic $\mathrm{db} / \mathrm{db}$ mice. Biol Pharm Bull 2007;30:2196-200.

113. Gu J, Li W, Xiao D, et al. Compound K, a final intestinal metabolite of ginsenosides, enhances insulin secretion in MIN6 pancreatic $\beta$-cells by upregulation of GLUT2 . Fitoterapia 2013;87:84-8.

114.Li W, Zhang M, Gu J, et al. Hypoglycemic effect of protopanaxadiol-type ginsenosides and compound $\mathrm{K}$ on Type 2 diabetes mice induced by high-fat diet combining with streptozotocin via suppression of hepatic gluconeogenesis. Fitoterapia 2012;83:192-8.

115.Jiang S, Ren D, Li J, et al. Effects of compound K on hyperglycemia and insulin resistance in rats with type 2 diabetes mellitus. Fitoterapia 2014;95:58-64.

116. Wei S, Li W, Yu Y, et al. Ginsenoside Compound K suppresses the hepatic gluconeogenesis via activating adenosine-5'monophosphate kinase: A study in vitro and in vivo. Life Sci 2015;139:8-15.

117. Chen W, Wang J, Luo Y, et al. Ginsenoside Rb1 and compound $\mathrm{K}$ improve insulin signaling and inhibit ER stress-associated NLRP3 inflammasome activation in adipose tissue. J Ginseng Res 2016;40:351-8.

118.Huang YC, Lin CY, Huang SF, et al. Effect and mechanism of ginsenosides $\mathrm{CK}$ and $\mathrm{Rg} 1$ on stimulation of glucose uptake in 3T3-L1 adipocytes. J Agric Food Chem 2010;58:6039-47.

119. Guan FY, Gu J, Li W, et al. Compound K protects pancreatic islet cells against apoptosis through inhibition of the AMPK/JNK pathway in type 2 diabetic mice and in MIN6 $\beta$-cells. Life Sci 2014;107:42-9.

120.Kim K, Park M, Lee YM, et al. Ginsenoside metabolite compound $\mathrm{K}$ stimulates glucagon-like peptide-1 secretion in NCI-H716 cells via bile acid receptor activation. Arch Pharm Res 2014;37:1193-200.

121. Song W, Wei L, Du Y, et al. Protective effect of ginsenoside metabolite compound $\mathrm{K}$ against diabetic nephropathy by inhibiting NLRP3 inflammasome activation and $\mathrm{NF}-\kappa \mathrm{B} / \mathrm{p} 38$ signaling pathway in highfat diet/streptozotocin-induced diabetic mice. Int Immunopharmacol 2018;63:227-38.

122.Zong W, Zeng X, Chen S, et al. Ginsenoside compound
$\mathrm{K}$ attenuates cognitive deficits in vascular dementia rats by reducing the $\mathrm{A} \beta$ deposition. J Pharmacol Sci 2019;139:223-30.

123. Guo J, Chang L, Zhang X, et al. Ginsenoside compound $\mathrm{K}$ promotes $\beta$-amyloid peptide clearance in primary astrocytes via autophagy enhancement. Exp Ther Med 2014;8:1271-4.

124. Chen X, Li H, Yang Q, et al. Ginsenoside compound K ameliorates Alzheimer's disease in HT22 cells by adjusting energy metabolism. Mol Biol Rep 2019;46:5323-32.

125. Song W, Guo Y, Jiang S, et al. Antidepressant Effects of the Ginsenoside Metabolite Compound K, Assessed by Behavioral Despair Test and Chronic Unpredictable Mild Stress Model. Neurochem Res 2018;43:1371-82.

126. Lee BH, Hwang SH, Choi SH, et al. Inhibitory Effects of Ginsenoside Metabolites, Compound K and Protopanaxatriol, on GABAC Receptor-Mediated Ion Currents. Korean J Physiol Pharmacol 2013;17:127-32.

127.Zeng X, Hu K, Chen L, et al. The Effects of Ginsenoside Compound K Against Epilepsy by Enhancing the $\gamma$-Aminobutyric Acid Signaling Pathway. Front Pharmacol 2018;9:1020.

128. Yamada N, Araki H, Yoshimura H. Identification of antidepressant-like ingredients in ginseng root (Panax ginseng C.A. Meyer) using a menopausal depressive-like state in female mice: participation of 5-HT2A receptors. Psychopharmacology (Berl) 2011;216:589-99.

129. Shin KO, Seo CH, Cho HH, et al. Ginsenoside compound $\mathrm{K}$ inhibits angiogenesis via regulation of sphingosine kinase-1 in human umbilical vein endothelial cells. Arch Pharm Res 2014;37:1183-92.

130. Lee ES, Choi JS, Kim MS, et al. Ginsenoside metabolite compound $\mathrm{K}$ differentially antagonizing tumor necrosis factor- $\alpha$-induced monocyte-endothelial trafficking. Chem Biol Interact 2011;194:13-22.

131.Lu S, Luo Y, Zhou P, et al. Ginsenoside compound K protects human umbilical vein endothelial cells against oxidized low-density lipoprotein-induced injury via inhibition of nuclear factor- $\kappa \mathrm{B}, \mathrm{p} 38$, and JNK MAPK pathways. J Ginseng Res 2019;43:95-104.

132.Park ES, Lee KP, Jung SH, et al. Compound K, an intestinal metabolite of ginsenosides, inhibits PDGF-BBinduced VSMC proliferation and migration through G1 arrest and attenuates neointimal hyperplasia after arterial injury. Atherosclerosis 2013;228:53-60.

133. Tsutsumi YM, Tsutsumi R, Mawatari K, et al. Compound $\mathrm{K}$, a metabolite of ginsenosides, induces cardiac protection mediated nitric oxide via Akt/PI3K pathway. Life Sci 
2011;88:725-9.

134.Li X, Huang Q, Wang M, et al. Compound K Inhibits Autophagy-Mediated Apoptosis Through Activation of the PI3K-Akt Signaling Pathway Thus Protecting Against Ischemia/Reperfusion Injury. Cell Physiol Biochem 2018;47:2589-601.

135.Lee CS, Bae IH, Han J, et al. Compound K inhibits MMP1 expression through suppression of c-Src-dependent ERK activation in TNF- $\alpha$-stimulated dermal fibroblast. Exp Dermatol 2014;23:819-24.

136. Cai BX, Luo D, Lin XF, et al. Compound K suppresses ultraviolet radiation-induced apoptosis by inducing DNA repair in human keratinocytes. Arch Pharm Res 2008;31:1483-8.

137. He D, Sun J, Zhu X, et al. Compound K increases type I procollagen level and decreases matrix metalloproteinase-1 activity and level in ultraviolet-A-irradiated fibroblasts. J Formos Med Assoc 2011;110:153-60.

138. Kirtonia A, Sethi G, Garg M. The multifaceted role of reactive oxygen species in tumorigenesis. Cell Mol Life Sci 2020;77:4459-83.

139. Wang YS, Zhu H, Li H, et al. Ginsenoside compound K inhibits nuclear factor-kappa B by targeting Annexin A2. J Ginseng Res 2019;43:452-9.

140. Kang KA, Kim YW, Kim SU, et al. G1 phase arrest of the cell cycle by a ginseng metabolite, compound $\mathrm{K}$, in U937 human monocytic leukamia cells. Arch Pharm Res 2005;28:685-90.

141. Han J, Wang Y, Cai E, et al. Study of the Effects and Mechanisms of Ginsenoside Compound K on Myelosuppression. J Agric Food Chem 2019;67:1402-8.

142. Boshtam M, Asgary S, Kouhpayeh S, et al. Aptamers Against Pro- and Anti-Inflammatory Cytokines: A Review. Inflammation 2017;40:340-9.

Cite this article as: Liu T, Zhu L, Wang L. A narrative review of the pharmacology of ginsenoside compound K. Ann Transl Med 2022;10(4):234. doi: 10.21037/atm-22-501
143.Liu Y, Perumalsamy H, Kang CH, et al. Intracellular synthesis of gold nanoparticles by Gluconacetobacter liquefaciens for delivery of peptide CopA3 and ginsenoside and anti-inflammatory effect on lipopolysaccharideactivated macrophages. Artif Cells Nanomed Biotechnol 2020;48:777-88.

144. Wang B, Dong J, Xu J, et al. Ginsenoside CK inhibits obese insulin resistance by activating PPAR $\gamma$ to interfere with macrophage activation. Microb Pathog 2021;157:105002.

145.Wu CY, Hua KF, Hsu WH, et al. IgA Nephropathy Benefits from Compound K Treatment by Inhibiting NFผB/NLRP3 Inflammasome and Enhancing Autophagy and SIRT1. J Immunol 2020;205:202-12.

146.Aboyans V. Introducing the 2019 ESC Guidelines on Diabetes, Pre-Diabetes, and CVD. Eur Heart J 2019;40:3217-9.

147. Brubaker PL. Minireview: update on incretin biology: focus on glucagon-like peptide-1. Endocrinology 2010;151:1984-9.

148. Mueller KD, Koscik RL, Du L, et al. Proper names from story recall are associated with beta-amyloid in cognitively unimpaired adults at risk for Alzheimer's disease. Cortex 2020;131:137-50.

149. Hou JG, Xue JJ, Lee MR, et al. Compound K is able to ameliorate the impaired cognitive function and hippocampal neurogenesis following chemotherapy treatment. Biochem Biophys Res Commun 2013;436:104-9.

150. Wang H, Qu F, Xin T, et al. Ginsenoside Compound K Promotes Proliferation, Migration and Differentiation of Schwann Cells via the Activation of MEK/ERK1/2 and PI3K/AKT Pathways. Neurochem Res 2021;46:1400-9.

(English Language Editor: J. Jones) 